\title{
An overview of the applications of furfural and its derivatives
}

\author{
Anthonia, E. Eseyin*, Philip, H. Steele \\ Department of Sustainable Bioproducts, Mississippi State University, USA \\ *Corresponding author E-mail: eseyinae@gmail.com
}

\begin{abstract}
Recently, furfural, "the sleeping beauty bio-renewable chemical" has gained a renewed attention as a potential chemical for the production of biofuels and biochemicals. Furfural is the most commonly produced industrial chemical because its production is very flexible. It is one of the top value-added chemicals that can be produced from biomass. Furfural and its derivatives have been extensively used in plastics, pharmaceutical and agrochemical industries. Furfural is a natural precursor to a range of furan-based chemicals and solvents such as dihydropyran, methyltetrahydrofuran, tetrahydrofuran, methylfuranfurfuryl alcohol, tetrahydrofurfuryl alcohol and furoic acid. Furfural and its derivatives have been widely applied as fungicides and nematicides, transportation fuels, gasoline additives, lubricants, resins, decolorizing agents, jet fuel blend stocks, drugs, insecticides, bio-plastics, flavor enhancers for food and drinks, rapid all-weather repair system for bomb-damaged runways and pot holes and also for wood modification and book preservation.
\end{abstract}

Keywords: Furfural; Furfuryl Alcohol; Tetrahydrofuran; Furoic Acid; 5-Methyl Furfural.

\section{Introduction}

Lignocellulosic biomass has drawn a lot of attention because of its high carbohydrate content. Lignocellulosic biomass contains approximately $42-54 \%$ cellulose, $23-36 \%$ hemicellulose and $22-28 \%$ lignin. Cellulose is a polymer of glucose and hemicellulose, and it is composed of pentose and hexose (Nigam and Singh 2010). Hemicellulose derived from wood is the most abundant polymer in lignocellulosic biomass. It contains pentose (xylose and arabinose) and can be used as raw material to obtain various chemical products. Among these acids are succinic, itaconic, levulinic, glucaric, aspartic, 2,5-furan dicarboxylic, glutaric, 3hydroxypropionic, 3-hydroxybutyric as well as beta-lactone, sorbitol, xylitol, glycerol, and furfural (Sun and Cheng 2002; Riansangawong and Prasertsan 2011). Furfural is the most frequently produced industrial chemical. The production of furfural is very flexible and as such. It is one of the top value-added chemicals that can be produced from biomass (Werpy and Petersen 2004; Bozell and Petersen 2010; Dutta et al. 2012a).

The Quaker Oats company started the industrial production of furfural in 1921, using oat hulls, corn cobs and sugar cane bagasse. However, because of limited demand and high-maintenance costs (Brownlee and Miner 1948), the yield of furfural and its production methods have not improved significantly since the 1980s (Zeitsch 2000a).Currently, most of the furfural on the world market is produced in China. About 300-700 Ktons of furfural is produced annually worldwide (Win 2005; Mao et al. 2012). This value represents more than half of the global capacity (Win 2005). The Chinese production capacity is characterized by widespread inefficient small-scale fixed bed processes. In order for furfural and its derivatives to compete with petroleum-based products as renewable alternatives, improvements in yields and production strategies are required. Furfural can also be produced by dehydrating pentose sugars or by the acid hydrolysis of biomass obtained from cornstalks and corncobs, peanut shells, wheat straw, sugar cane bagasse, cotton stalks, wood chips and other waste products (Saha 2003; Akpinar et al. 2009).

\section{Furfural production}

The preferred feedstock for furfural production are agricultural residues due to their homogeneity and regular availability in large quantities from food processing plants (Montane et al. 2002). Furfural is exclusively produced from lignocellulosic biomass by dehydrating pentose. Furfural can be produced by a one-step or a two-step process. In the one-step process, pentosans are hydrolyzed into xylose and then dehydrated into furfural simultaneously. However, in the two- step process, hydrolysis of pentosans occurs under mild conditions followed by the dehydration of xylose into furfural (Perego and Bianchi 2010; Serrano et al. 2010). The advantage of the two-step process is that a higher quantity of furfural is produced when compared to the one-step process. Again, solid residues are less degraded and can be converted to other chemicals such as ethanol, phenol, glucose and others in the subsequent step by fermentation.

The commercial production of furfural is by the acid hydrolysis of pentosan polysaccharides from non-food residues of food crops and wood wastes from fibrous residues of food crops. The precursors of furfural are the xylan, arabinan and pentosan contents of the raw biomass. The composition of these contents must be between $25-40 \%$. Furfural occurs naturally in many foods and is formed during the combustion of coal and wood. Humans are exposed to furfural during its production and use.

Furfural is produced industrially by the use of batch or continuous reactors. In this process, the pentosan fraction of the lignocellulose is converted into monosaccharides (pentoses) by acid hydrolysis. When these pentoses are further dehydrated, furfural is produced. 
The feedstock is loaded to the digester and mixed with an aqueous solution of inorganic acids. The desired reaction temperature of the system is maintained by the addition of steam to the digester. In order to minimize its loss through secondary reactions of degradation and condensation, furfural is continuously extracted from the reactor by steam distillation in a series of distillation columns. Methanol and acetic acid may also be obtained as marketable byproducts, depending on the configuration of the separation process. The solid residue is separated from the liquid at the end of the reaction period and may be processed to recover the acid catalyst. The residual solid consists of lignin and depolymerized cellulose. This solid may be dried and burned in a boiler to provide steam for the reactor. Several digesters are operated in a coordinated rotation when batch reactors are used in order for the distillation plant to be operated continuously. The reaction conditions for furfural production are: $3 \%$ acid solution to lignocellulosic mass ratios of between $2: 1$ and $3: 1$, reaction temperatures of around $170-185{ }^{\circ} \mathrm{C}$ and $3 \mathrm{~h}$ reaction time. The potential maximum furfural yields are between $45 \%$ and $50 \%$ with this technology (Montane et al. 2002).

Recently, the use of solid acid catalysts in a one-step process to replace the use of mineral acids in a two-step process was reported (Dhepe and Sahu 2010; Sahu and Dhepe 2012).However, because of issues relating to morphological changes of catalysts during furfural production, Bhaumik and Dhepe (Bhaumik and Dhepe 2014) developed a stable solid acid catalyst for the efficient conversion of hemicellulose into furfural in a one-pot process. The schematic for this process is presented in Fig. 1.

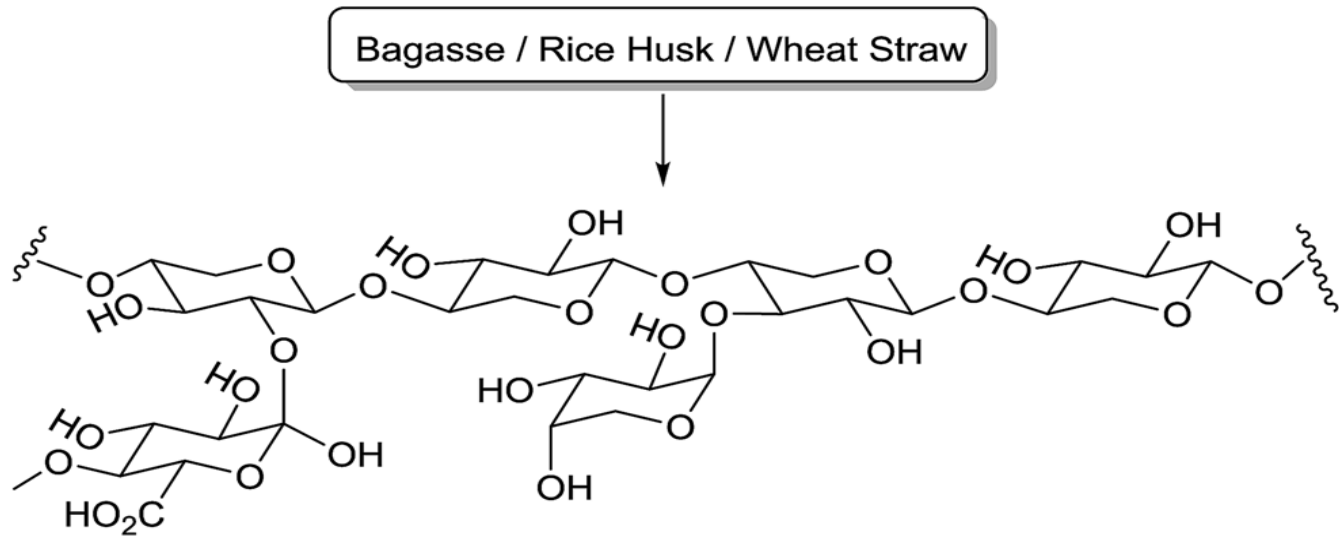

Hemicellulose

Solid acid $\downarrow \mathrm{H}_{2} \mathrm{O}, \triangle$

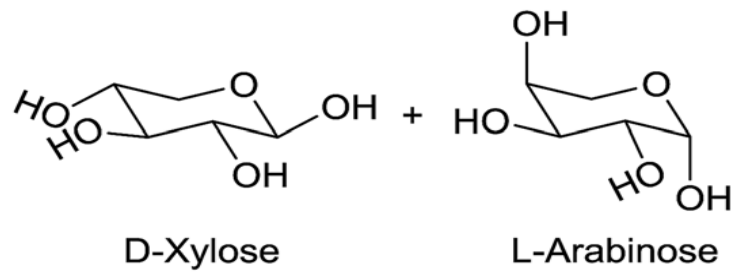<smiles>O=Cc1ccco1</smiles>

Furfural

Fig. 1: One-Pot Conversion of Hemicellulose to Furfural, Using a Solid Acid Catalyst. Source: (Bhaumik and Dhepe 2014)

Furfural (furan-2-carboxaldehyde) is a viscous, colorless liquid with a boiling point of about $160{ }^{\circ} \mathrm{C}$. It has a pleasant aromatic odor and turns dark, brown or black when exposed to air. Furfural is a natural precursor to a range of furan-based chemicals and solvents such as dihydropyran, methyltetrahydrofuran, tetrahydrofuran, methylfuranfurfuryl alcohol, tetrahydrofurfuryl alcohol and furoic acid. Furanic components can be upgraded by the hydrogenation of the aldehyde group or furan ring. This very versatile reaction can also be employed in synthesizing hydrocarbon fuels directly from furan derivatives. Alcohols such as 1, 5-pentanediol can be produced by cleavage of the furan ring through hydrogenolysis (Hurd et al. 1933; Brownlee and Miner 1948; Cass 1948; Wojcik 1948; Merat et al. 1990; Hoydonckxet al. 2000; Huber and Dumesic 2006; Corma et al. 2007; Sitthisa et al. 2011; Lange et al.
2012; Pace et al. 2012). Currently, furfural production does not require expensive pilot plants or the construction of the nextgeneration biorefineries.

\section{Studies on furfural production}

Karimi and co-researchers (Karimi et al. 2006) investigated the production of furfural at higher pressures (10-25 bar) and temperatures $(220-240 \circ \mathrm{C})$ while Montane et al. (Montane et al. 2002) and Eken-Saracoglu et al. (Eken-Saracoglu et al. 1998) employed short reaction times. Other researchers employed the hydrolysis of lignocellulosic waste materials in the presence of mineral acid catalysts. Lavarack et al. (Lavarack et al. 2002) and Herrera et al. (Herrera et al. 2003) employed the use of $\mathrm{HCl}$. Rodriguez-Chong 
et al. (Rodriguez-Chong et al. 2004) used $\mathrm{HNO}_{3}$ while Rahman et al. (Rahman et al. 2006) employed $\mathrm{H}_{2} \mathrm{SO} 4$. However, Vazquez et al. (Vazquez, et al. 2007) and Lenihan et al. (Lenihan et al. 2010) employed the use of $\mathrm{H}_{3} \mathrm{PO}_{4}$ while Yang and Sen (Yang and Sen 2011) utilized HI (hydroiodic acid)

Some other researchers have also investigated the utilization of many liquid solvents as reaction media instead of water, to reduce or eliminate the generation of acidic effluent in furfural production. Campos et al. (Campos et al. 2012) used organic solvents while Guerbuez et al. (Guerbuez et al. 2012), Yang Yang et al. (Yang et al. 2012a) and Xing et al. (Xing et al. 2011) used water/organic solvent biphasic systems. The employment of novel catalysts for the production of furfural has been proposed. Chareonlimkun et al. (Chareonlimkun et al. 2010) proposed the use of oxides, Lamminpaa et al. (Lamminpaa et al. 2012), Yang et al. (Yang et al. 2012b) and Yang et al. (Yang et al. 2013) proposed the use of organic acids. Binder et al. (Binder et al. 2010), Dutta et al. (Dutta et al. 2012b) and vom Stein et al. (vom Stein et al. 2011) suggested metal chlorides while Weingarten et al. (Weingarten et al. 2011), Forstner et al. (Forstner et al. 2012) and Hua et al. (Hua et al. 2013) proposed the employment of solid catalysts.

Metal chlorides have remarkably improved the reaction rate of xylose conversion because they have been able to induce an alternative mechanism for xylose dehydration into furfural through the formation of xylulose (Choudhary et al. 2012; Yang et al., 2012b) However, the employment of metal chlorides for furfural production could reduce corrosion problems associated with mineral acid catalysts thereby avoiding the deactivation of solid acid catalysts.

\section{Applications of furfural}

\subsection{Furfural as a solvent}

Furfural is the sleeping beauty of all the bio-renewable chemicals bioplastics and polymers. Furfural and its derivatives have wide applications in many industries such as plastics, pharmaceuticals and agrochemicals, etc. (Mamman et al. 2008). Furfural is commonly used as a solvent; it is soluble in ethanol and ether and somewhat soluble in water. The aldehyde group and furan ring in furfural confers the furfural molecule with outstanding properties as a selective solvent (Sain et al. 1982; Zeitsch 2000b; Hoydonckx 2008). Furfural is a reactive solvent, an excellent wetting agent who has the ability to form a conjugated double bond complex with molecules containing double bonds. It is used industrially for the extraction of aromatics from lubricating oils and diesel fuels or unsaturated compounds from vegetable oils and also in wax recovery. It is a solvent for the manufacture of phenolic resins. Synthetic rubber is made by the purification technology of butadiene or isoprene, and furfural plays an important role in the extractive distillation of butadiene.

\subsection{Furfural as transportation fuel, gasoline additive, lubricant, resin and decolorizing agent}

The aldol condensation of furfural and acetone followed by hydrogenation leads to the production of high yields of liquid alkanes which are used as transportation fuels (Huber et al. 2005). Furfural is often used as an agent for decolorizing crude wood rosin. It is used widely as a solvent in petroleum refining, lubricants and specialist adhesives. Furfural can be converted by hydrogenation to 2-methylfuran and 2-methyltetrahydrofuran which are used as gasoline additives. Furfural as well as furfuryl alcohol can be used individually or in combination with phenol, acetone or urea to make resins in the production and manufacture of casting molds, automotive brake linings, abrasive wheels, refectory products of the steel industry, fiberglass and some aircraft components.

\subsection{Furfural as an intermediate in the synthesis of pharmaceuticals, chemicals and biopolymers}

Furfural is an essential part of pharmaceutical building blocks. It is used in the manufacture of furan, an intermediate in the synthesis of pharmaceuticals, agricultural and fine chemicals as well as stabilizers. Furfural, made from biomass has been used to showcase the synthesis of alternatives to petrochemical derived polymers (polyesters) (Tachibana 2012) which are used as drop-in substitute to manufacture bio-renewable plastics because of their similarity with their petrochemical equivalents. Bio-renewable polyethylene furanoate is an alternate and green plastic, used for soft drink bottles. Bioplastics are also used extensively for consumer electronics, automotive accessories, packaging, catering products and toys (www.bio-based.eu/markets).

Furfural is also used in the formation of spandex, a synthetic fiber (polyurethane-polyurea copolymer), known for its exceptional elasticity. However, it is strong, but less durable than natural latex, which is its major non-synthetic competitor. Furfural is an efficient lignin-crosslinking agent that can replace formaldehyde in wood glues. It is used in formulations for rigid and flexible polyurethanes, which go into automotive packaging and furniture industries for use as foams, coatings, adhesives, sealants, etc.

\subsection{Furfural as a jet fuel blendstock}

Furfural and its derivatives have the potential to make jet fuel range alkenes and to serve as gasoline blendstock (Xing et al. 2011). Furfuryl alcohol was one of components used as hypergolic starter fluids that ignite liquid rocket fuels spontaneously in space shuttles. These starter fluids also ignite in the absence of oxygen (i.e. in space).

\subsection{Furfural in books}

The papers in books contain hemicelluloses which are the sources of furfural. Furfural is one of the many chemicals that contribute to the aroma of books. The gradual degradation of the complex mixture of volatile chemicals within paper, used in the manufacture of books, produces the aroma of books which is associated with furfural.

\subsection{Furfural residues as soil enhancers and organic fer- tilizers}

Furfural residues are carbon rich, acidic $(\mathrm{pH}=2)$ and contain valuable nutrients (Chun'aiet al. 2010 ). Cai et al. (Cai et al. 1998) reported that furfural residues can be used to improve properties such as the $\mathrm{pH}$ (reduced alkalinity), bulk density, compactness, water permeability and retention ability of soil. Xin et al. (Xin et al. 2009) also recently proposed a production method for a soil fertilizer, consisting of a mixture of solid residues from seaweed and furfural processing units. This multifunctional organic fertilizer, with a wide application range is easy to prepare at low integrated cost and has also shown remarkably positive effects on crop yields.

\subsection{Furfural as fungicide and nematicide}

Furfural is used in agriculture/horticulture as a weed killer (Zeitsch 2000). Furfural is the active ingredient in several nematicides such as Crop guard and protected, which are currently used in parts of Africa (Hensley and Burger2006). Furfural, being a contact nematicide is used in relatively low concentrations (Zeitsch 2000b) and mechanically incorporated or moved into the soil profile during irrigation (Rodri'guez-Ka'bana 1993) As an agrochemical, furfural is relatively safe and easy to apply. 


\subsection{Furfural as flavour enhancer for food and drinks}

Furfural is generally recognized as safe. It is a natural degradation product of vitamin $\mathrm{C}$ (ascorbic acid) and it is a significant component of wines and fruit juices. 'The older the wine, the more the furfural'. Despite the fact that furfural has an LD50 of $2330 \mathrm{mg} \mathrm{kg}$ ${ }^{1}$ for dogs, its toxicity to humans is relatively low (Zeitsch 2000b). Cocoa and coffee have the highest concentrations of furfural (55$255 \mathrm{ppm}$ ). Its concentration in alcoholic beverages is 1-33 ppm and 0.8-26 ppm in brown bread (Kroes1999). Furfural is also present in some essential oils, foods, and cosmetic products.

\section{Applications of furfural derivatives}

Like furfural, its derivatives also have a high demand for application in the plastic, food, pharmaceutical and agricultural industries (Dias et al. 2005; Dias et al. 2006).

\subsection{For pharmaceutical, agricultural and industrial chemicals}

Furoic acid is the first down-line oxidation derivative of furfural It is a versatile starting material for the synthesis of pharmaceutical, agricultural and industrial chemicals. Furoic acid is extensively converted to furoyl chloride, used in the production of drugs and insecticides. The furan ring is an important pharmacophore in modern drug discovery. Furfuryl alcohol, methylfuran and nitrofurans are employed in making antimicrobial agents. Furan is also deployed as a chemical intermediate and solvent. Tetrahydrofurfuryl alcohol is a widely used precursor in the production of specialty chemicals. It is also employed as a catalyst binder for new pebble-bed reactors (Eastman and Crandell2003). 5-chloromethyl furfural can be synthesized to prothrin, a synthetic pyrethroid insecticide.

\subsection{As resins}

The most important derivative of furfural is furfuryl alcohol, which is used as a basic component for furan resins (Mansilla et al. 1998; Vazquez et al. 2007). When phenols are reacted with the corresponding furfural derivatives, furfuryl alcohol, used in the production of thermosetting furan resin and furan cement is formed (Brydson 1999; Ibeh 1999). Furfuryl alcohol is used in the production of furane resin, surface coatings, mortar, chemically resistant resins, boiler floor grouting and also in the production of adhesives, used in foundry cores and molds.

Furan is a family of organic compounds of the heterocyclic aromatic series, characterized by a five-membered aromatic ring, consisting of four $\mathrm{CH}_{2}$ groups and one oxygen atom. Furan resins, having excellent chemical and heat transfer resistances have a wide range of applications as foundry sand binders, chemically resistant cements and as laminates in chemical plants (Brydson 1999). Furthermore, user-friendly furan resin systems have been developed for a variety of composite applications in the automotive and building industries as the interior of aircraft cabins, internal fittings for buildings and rail carriages (Kumar and Anandjiwala 2013; Hoydonckx and Van Rhijn 2008).

\subsection{As a rapid all-weather repair system for bomb- damaged runways and pot holes}

During the Vietnam and other wars, furfuryl alcohol based polymer systems were successfully applied in all-weather conditions to quickly repair bomb-damaged runways (Sugama et al. 2014).

The resulting compressive strength and durability are equal to that of the original surface. However, South Africa adopted this system and demonstrated field tests, proving that bio-based chemicals (in this case sugarcane bagasse derived furfuryl alcohol) competes well with, or even better than crude-oil derived epoxy resins (Kruger 1987)

\subsection{In polymer and plastic industries}

Furfural and many of its derivatives can be used for the synthesis of specialty polymers depending on the chemistry of the furan ring (Sain et al. 1982; Gandini and Belgacem 1997; Moreau et al. 2004; Hoydonckx et al. 2008). Tetrahydrofuran is a precursor for a wide range of chemical syntheses (Penn. Specialty 2001; BASF 2002). When furfural is hydrogenated, tetrahydrofuran is formed. Tetrahydrofuran is a very important commercial solvent used as the starting material in the production of nylon and polytetramethylene ether glycols (spandex) by polymerizing tetrahydrofuran. Polyester is a synthetic polymer made of purified terephthalic acid. Furan-2, 5-dicarboxylic acid, an important renewable building block that can substitute for terephthalic acid in the production of polyesters is produced from furoic acid.

Polytetramethylene ether glycol or polytetrahydrofuran is a polymer, used in the manufacture of spandex fiber (e.g. InvistaLycra $\left.{ }^{\circledR}\right)$ and polyurethanes. Currently, they are produced from crude-oil derived chemicals. However, the synthesis of its green equivalent can be achieved via furfural, furan, tetrahydrofuran or polytetramethylene ether glycols.

\subsection{Wood modification and book preservation}

Furfural stops tropical deforestation, which is responsible for greenhouse gas emissions. Furfuryl alcohol, a derivative of furfural is the main ingredient in wood-modification processes that convert softwoods to products that look like and have properties that are similar to tropical hardwoods. Furfurylation of wood produces non-toxic woods, suitable for internal and external applications that demand high performance and good aesthetic appearance such as playgrounds, floors, cladding, etc.

\subsection{Furfuryl alcohol and the space shuttle}

Furfuryl alcohol has been used in reinforced carbon-carbon composite materials, developed to protect the shuttle around its nose and wing leading edge from extremely high and cold temperatures $\left(-121\right.$ to $\left.1,649^{\circ} \mathrm{C}\right)$ encountered during the re-entry of shuttles into space. NASA created the US space shuttle orbiter thermal protection system (Pirolini 2015). In this system, after pyrolysis and rough trimming of graphite fabric, the polymer resin is converted into carbon, which is then impregnated with furfuryl alcohol. With further pyrolysis, the density of this material is increased leading to improved mechanical properties.

\section{Future applications of furfural}

A furfural derived compound, methyltetrahydrofuran, has the potential application for green fuel production in the so-called $\mathrm{P}$ series, developed in USA (Kar and Deveci 2006). However, methyltetrahydrofuran is also considered as a platform chemical for the near future. An investigation, supported by US DOE to identify the most promising platform chemicals, revealed that furfural and two of its derivatives, furan dicarboxylic acid and levulinic acid were ranked among the list of 30 chemicals. There is a forecast as to how their core binders will adapt to the future demands of environmental regulations, extended shelf life and tighter dimensional accuracy that are currently bottlenecks of the metal casting industry (Tackes 2001).

\section{Conclusion}

There is a renewed interest in the production of transportation fuels and chemicals from renewable sources. Lignocellulosic biomass is one of the world's most abundant and renewable resources. Furfural is exclusively produced from lignocellulosic biomass by dehydrating pentose in a one-step or two-step process. Currently, furfural production does not require expensive pilot plants or the construction of the next-generation biorefineries. 
Furfural, made from biomass has been extensively used to showcase the synthesis of alternatives to petrochemical derived polymers. Furfural is a natural precursor to a range of furan-based chemicals and solvents and has been widely used in the plastics, pharmaceutical and agrochemical industries. Furfural and its derivatives are used in the production of drugs, insecticides, polymers, plastics, adhesives, resins, specialty chemicals, transportation fuels, gasoline additives, lubricants, decolorizing agents and in many more applications.

\section{References}

[1] Akpinar, O., Erdogan, K., \& Bostanci, S. (2009). Production of xylooligosaccharides by controlled acid hydrolysis of lignocellulosic materials. Carbohydr. $\quad$ Res., 344, 660-666. http://dx.doi.org/10.1016/j.carres.2009.01.0150.

[2] BASF. (2002). BASF and Lyondell boost THF production (China/US).Specialty Chemicals, October.

[3] Bhaumik, P., \& Dhepe, P. L. (2014). Exceptionally high yields of furfural from assorted raw biomass over solid acids. RSC Adv., 4 , 26215-26221. http://dx.doi.org/10.1039/c4ra04119d.

[4] Binder, J. B., Blank, J. J., Cefali, A. V., \& Raines, R. T. (2010). Synthesis of furfural from xylose and xylan. ChemSusChem, 3, 12681272. http://dx.doi.org/10.1002/cssc.201000181.

[5] Bozell, J. J., \& Petersen, G. R. (2010). Technology development for the production of biobased products from biorefinery carbohydratesThe US Department of Energy's "Top 10" revisited. Green Chem., 12 539-554. http://dx.doi.org/10.1039/b922014c.

[6] Brownlee, H. J., \& Miner, C. S. (1948). Industrial development for furfural. Ind. Eng. Chem., 40, 201-204. http://dx.doi.org/10.1021/ie50458a005.

[7] Brydson, J. A. (1999). 28-Furan resins: Plastics Materials (Seventh Edition) Butterworth Heinemann, Oxford, pp.810-813. http://dx.doi.org/10.1016/B978-075064132-6/50069-3.

[8] Cai, A.X., Song, R.H., \& Jiang, Z. Q. (1998). Effect of furfural residue on control of soil alkalization and amelioration of solonetz. Pedoshpere, 8, 343-348

[9] Campos Molina, M. J., Mariscal, R., Ojeda, M., \& Lopez Granados, M. (2012). Cyclopentyl methyl ether: a green co-solvent for the selective dehydration of lignocellulosic pentoses to furfural. Bioresour. Technol., 126 ,

321-327. http://dx.doi.org/10.1016/j.biortech.2012.09.049.

[10]Cass, O. W. (1948). Chemical intermediates from furfural. Ind. Eng Chem., 40, 216-219. http://dx.doi.org/10.1021/ie50458a008.

[11]Chareonlimkun, A., Champreda, V., Shotipruk, A., \& Laosiripojana, N. (2010). Catalytic conversion of sugarcane bagasse, rice husk and corncob in the presence of $\mathrm{TiO}_{2}, \mathrm{ZrO}_{2}$ and mixed-oxide $\mathrm{TiO}_{2}-\mathrm{ZrO}_{2}$ under hot compressed water (HCW) condition. Bioresour. Technol. 101, 4179-4186. http://dx.doi.org/10.1016/j.biortech.2010.01.037.

[12]Choudhary, V., Sandler, S. I., \& Vlachos, D. G. (2012). Conversion of xylose to furfural using Lewis and Bronsted acid catalysts in aqueous media. ACS $\quad$ Catal., $2022-2028$ http://dx.doi.org/10.1021/cs300265d.

[13]Chun'ai D., Bo, L., Girisuta, B., \& Heeres, H. J. (2010). Research progress on furfural residues recycling: A Literature review. Paper presented at the International Conference on Environmental Engineering and Applications (ICEEA)

[14]Corma, A., Iborra, S., \& Velty, A. (2007). Chemical routes for the transformation of biomass into chemicals. Chem. Rev., 107, 24112502. http://dx.doi.org/10.1021/cr050989d.

[15]Dhepe, P. L., \& Sahu, R. (2010). A solid-acid-based process for the conversion of hemicellulose. Green Chem., 12, 2153-2156. http://dx.doi.org/10.1039/c004128a

[16]Dias, A. S., Lima, S., Pillinger, M., \& Valente, A. A. (2006). Acidic cesium salts of 12-tungstophosphoric acid as catalysts for the dehydration of xylose into furfural. Carbohydr. Res., 341, 2946-2953. http://dx.doi.org/10.1016/j.carres.2006.10.013.

[17]Dias, A. S., Pillinger, M., \& Valente, A. A. (2005). Dehydration of xylose into furfural over micro-mesoporous sulfonic acid catalysts. J. Catal., 229, 414-423. http://dx.doi.org/10.1016/j.jcat.2004.11.016

[18]Dutta, S., De, S., Saha, B., \& Alam, M. I. (2012a). Advances in conversion of hemicellulosic biomass to furfural and upgrading to biofuels. Catal. Sci. Technol., 2025-2036. http://dx.doi.org/10.1039/c2cy20235b.

[19]Dutta, S., De, S., Alam, M. I., Abu-Omar, M. M., \& Saha, B. (2012b). Direct conversion of cellulose and lignocellulosic biomass into chemicals and biofuel with metal chloride catalysts. J. Catal., 288, 8-15. http://dx.doi.org/10.1016/j.jcat.2011.12.017.
[20]Eastman, J., \& Crandell, G. (2003). Putting GMBOND to the test. Available at: http://foundrymag.com (accessed 20 May, 2015).

[21]Eken-Saracoglu, N., Mutlu, S. F., Dilmac, G., \& Cavusoglu, H. (1998). A comparative kinetic study of acidic hemicellulose hydrolysis in corn cob and sunflower seed hull. Bioresour. Technol., 65, 29-33. http://dx.doi.org/10.1016/S0960-8524(98)00032-7.

[22] Forstner, J., Unkelbach, U., Pindel, E., \& Schweppe, R. (2012). Heterogen katalysierte herstellung von furfural aus xylose. Chem. Ing. Tech., 84, 503-508. http://dx.doi.org/10.1002/cite.201100178.

[23] Gandini, A., \& Belgacem, M. N. (1997). Furans in polymer chemistry. Prog. Polym. Sci., 22, 1203-1379. http://dx.doi.org/10.1016/S00796700(97)00004-X.

[24] Global production capacities of bioplastics. Available at: www.biobased.eu/markets. (accessed 20 May, 2015).

[25] Guerbuez, E. I., Wettstein, S. G., \& Dumesic, J. A. (2012). Conversion of hemicellulose to furfural and levulinic acid using biphasic reactors with alkylphenol solvents. ChemSusChem, 5, 383-387. http://dx.doi.org/10.1002/cssc. 201100608.

[26] Hensley, J., \& Burger, G. (2006). Nematicidal properties of furfural and the development for nematode control in various crops for the United States markets. Journal of Nematology, 38, 274 (Abstr.).

[27]Herrera, A., Tellez-Luis, S. J., Ramirez, J. A., \& Vazquez, M. (2003). Production of xylose from sorghum straw using hydrochloric acid. J. Cereal Sci., 37, 267-274. http://dx.doi.org/10.1006/jcrs.2002.0510.

[28]Hoydonckx, H. E., \& Van Rhijn, W. M. (2008). Application of novel furan resins in composites. JEC Magazine.

[29]Hoydonckx, H. E., Van Rhijn, W. M., Van Rhijn, W., De Vos, D.E., \& Jacobs, P.A. (2000). Tetrahydrofuran. Ullmann's Encyclopedia of Industrial Chemistry: Wiley-VCH, Weinheim.

[30]Hoydonckx, H. E., Van Rhijn, W. M., Van Rhijn, W., De Vos, D.E., and Jacobs,P.A. (2008). Furfural and derivatives Ullmann's encyclopedia of industrial engineering Wiley-VCH, Weinheim.

[31]Hua, D., Li, P., Wu, Y., Chen, Y., Yang, M., Dang, J., Xie, Q.,Liu, J., \& Sun, X.-y. (2013). Preparation of solid acid catalyst packing AAO/SBA-15- $\mathrm{SO}_{3} \mathrm{H}$ and application for dehydration of xylose to furfural. J. Ind. Eng. Chem., 19, 1395-1399. http://dx.doi.org/10.1016/j.jiec.2013.01.002.

[32]Huber, G. W., Cheda, J. N., Barrett, C. J., \& Dumesic, J. A. (2005). Production of liquid alkanes by aqueous-phase processing of biomassderived carbohydrates. Science, 308, 1446-1450. http://dx.doi.org/10.1126/science.1111166.

[33]Huber, G. W., \& Dumesic, J. A. (2006). An overview of aqueousphase catalytic processes for production of hydrogen and alkanes in a biorefinery. Catal. Today, 111, 119-132. http://dx.doi.org/10.1016/j.cattod.2005.10.010.

[34]Hurd, C. D., Garrett, J. W., \& Osborne, E. N. (1933). Furan reactions IV. Furoic acid from furfural. J. Am. Chem. Soc., 55, 1082-1084. http://dx.doi.org/10.1021/ja01330a032.

[35]Ibeh, C. C. (1999). Amino and furan resins. (Andrew W Ed.) Handbook of Thermoset Plastics (2) pp. 72-96.

[36]Kar, Y., \& Deveci, H. (2006). Importance of P-series fuels for flexible-fuel vehicles (FFVs) and alternative fuels. Energy Sources, Part A, 28, 909-921. http://dx.doi.org/10.1080/00908310600718841.

[37] Karimi, K., Kheradmandinia, S., \& Taherzadeh, M. J. (2006). Conversion of rice straw to sugars by dilute-acid hydrolysis. Biomass Bioenergy, 30, 247-253. http://dx.doi.org/10.1016/j.biombioe.2005.11.015.

[38] Kroes, R. (1999). Safety evaluation of certain food additives. WHO food additives series: 42 .

[39]Kruger, D. (1987). Development of furfuryl alcohol polymer concrete for South African applications Available at http://hdl.handle.net/10210/12000 (accessed 24 May, 2015).

[40]Kumar, R., \& Anandjiwala, R. D. (2013). Compression-molded flax fabric-reinforced polyfurfuryl alcohol bio-composites. J. Therm. Anal. Calorim. 112, 755-760. http://dx.doi.org/10.1007/s10973-012-2623-9.

[41] Lamminpaa, K., Ahola, J., \& Tanskanen, J. (2012). Kinetics of xylose dehydration into furfural in formic acid. Ind. Eng. Chem. Res., 51, 6297-6303. http://dx.doi.org/10.1021/ie2018367.

[42]Lange, J.-P., van der Heide, E., van Buijtenen, J., \& Price, R. (2012). Furfural-a promising platform for lignocellulosic biofuels. ChemSusChem, 5, 150-166. http://dx.doi.org/10.1002/cssc.201100648.

[43]Lavarack, B. P., Griffin, G.J., Rodman,D., \& Tellez-Luis, S. J. (2002) The acid hydrolysis of sugar cane bagasse hemicelluloses to produce xylose, arabinose, glucose and otherproducts. Biomass Bioenergy 23, 367-338. http://dx.doi.org/10.1016/S0961-9534(02)00066-1.

[44]Lenihan, P., Orozco, A., O'Neill, E., Ahmad, M. N. M., Rooney, D., W., \& Walker, G. M. (2010). Dilute acid hydrolysis of lignocellulosic biomass. Chem. Eng. J., 156, 395-403. http://dx.doi.org/10.1016/j.cej.2009.10.061.

[45] Mamman, A. S., Lee, J.-M., Kim, Y.-C., Hwang, I. T., Park, N.-J., Hwang, Y. K., Chang, J.-S., \& Hwang, J.-S. (2008). Furfural: hemi- 
cellulose/xylose-derived biochemical. Biofuels, Bioprod. Biorefin., 2, 438-454. http://dx.doi.org/10.1002/bbb.95.

[46] Mansilla, H. D., Baeza, J., Urzua, S., Maturana, G., Villasenor, J., \& Duran, N. (1998). Acid-catalyzed hydrolysis of rice hulls: evaluation of furfural production. Bioresour. Technol., 66, 189-193. http://dx.doi.org/10.1016/S0960-8524(98)00088-1.

[47] Mao, L., Zhang, L., GAO, N., \& Li, A. (2012). $\mathrm{FeCl}_{3}$ and acetic acid co-catalyzed hydrolysis of corncob for improving furfural production and lignin removal from residue. Bioresour. Technol., 123, 324-331. http://dx.doi.org/10.1016/j.biortech.2012.07.058.

[48]Map to Furfural and its many By-products. Available at: http://www.dalinyebo.com/furfural (accessed 2 April, 2015).

[49]Merat, N., Godawa, C., \& Gaset, A. (1990). High selective production of tetrahydrofurfuryl alcohol: catalytic hydrogenation of furfural and furfuryl alcohol. J. Chem. Technol. Biotechnol., 48, 145-159. http://dx.doi.org/10.1002/jctb.280480205.

[50] Montane, D., Salvado, J., Torras, C., \& Farriol, X. (2002). Hightemperature dilute-acid hydrolysis of olive stones for furfural production. Biomass $\quad$ Bioenergy, 22, 295-304. http://dx.doi.org/10.1016/S0961-9534(02)00007-7.

[51] Moreau, C., Belgacem, M. N., \& Gandini, A. (2004). Recent catalytic advances in the chemistry of substituted furans from carbohydrates and in the ensuing polymers. Top. Catal. 27, 11-30. http://dx.doi.org/10.1023/B:TOCA.0000013537.13540.0e.

[52] Nigam, P. S., \& Singh, A. (2010). Production of liquid biofuels from renewable resources. Prog. Energy Combust. Sci., 37, 52-68. http://dx.doi.org/10.1016/j.pecs.2010.01.003.

[53]Pace, V. H. P., Castoldi, L., Domínguez de María, P., and Alcántara, A. R. (2012). 2-Methyltetrahydrofuran (2-MeTHF): a biomass-derived solvent with broad application in organic chemistry. ChemSusChem, 5 , 1369-1379. http://dx.doi.org/10.1002/cssc.201100780.

[54]Penn Specialty. (2001). Penn Specialty Completes 80 MM lb/yr THF Plant. Hydrocarbon Processing, April.

[55]Perego, C., \& Bianchi, D. (2010). Biomass upgrading through acidbase catalysis. Chem. Eng. J., 161, 314-322. http://dx.doi.org/10.1016/j.cej.2010.01.036.

[56] Pirolini, A. P. (2015). Materials used in space shuttle thermal protection systems. Available at: http://www.azom.com (accessed 2 April, 2015).

[57]Rahman, S. H. A., Choudhury, J. P., \& Ahmad, A. L. (2006). Production of xylose from oil palm empty fruit bunch fiber using sulfuric acid. Biochem. $\quad$ Eng. http://dx.doi.org/10.1016/j.bej.2006.02.009

[58] Riansa-ngawong, W., \& Prasertsan, P. (2011). Optimization of furfural production from hemicellulose extracted from delignified palm pressed fiber using a two-stage process. Carbohydr. Res., 346, 103110. http://dx.doi.org/10.1016/j.carres.2010.10.009.

[59]Rodrı'guez-Ka'bana, R., Kloepper, J. W., Weaver, C. F., \& Robinson, D. G. (1993). Control of plant parasitic nematodes with furfural-a naturally occurring fumigant. Nematropica, 23, 63-73.

[60]Rodriguez-Chong, A., Ramirez, J. A., Garrote, G., \&Vazquez, M (2004). Hydrolysis of sugar cane bagasse using nitric acid: a kinetic assessment. Journal of Food Engineering, 61, 143-152. http://dx.doi.org/10.1016/S0260-8774(03)00080-3.

[61] Saha, B. C. (2003). Hemicellulose bioconversion. J. Ind. Microbiol. Biotechnol., 30, 279-291. http://dx.doi.org/10.1007/s10295-003-0049$\underline{x}$.

[62]Sahu, R., \& Dhepe, P. L. (2012). A one-pot method for the selective conversion of hemicellulose from crop waste into C5 sugars and furfural by using solid acid catalysts. ChemSusChem, 5, 751-761. http://dx.doi.org/10.1002/cssc.201100448

[63] Sain, B., Chaudhuri, A., Borgohain, J. N., Baruah, B. P., \& Ghose, J. L. (1982). Furfural and furfural-based industrial chemicals. J. Sci. Ind. Res., 41, 431-438.

[64]Serrano, L., Eguees, I., Alriols, M. G., Llano-Ponte, R., \& Labidi, J. (2010). Miscanthus sinensis fractionation by different reagents. Chem Eng. J., 156, 49-55. http://dx.doi.org/10.1016/j.cej.2009.09.032.

[65]Sitthisa, S., an, W., \& Resasco, D. E. (2011). Selective conversion of furfural to methylfuran over silica-supported $\mathrm{Ni}-\mathrm{Fe}$ bimetallic cata$\begin{array}{llll}\text { lysts. } & \text { J. } & \text { Catal., } & \text { 284, }\end{array}$ http://dx.doi.org/10.1016/j.jcat.2011.09.005.

[66] Sun, Y., \& Cheng, J. (2002). Hydrolysis of lignocellulosic materials for ethanol production: a review. Bioresour. Technol., 83, 1-11. http://dx.doi.org/10.1016/S0960-8524(01)00212-7.

[67] Sugama, T., Kukacka, L.E., \& Horn, W. (2014). Water-compatible polymer concrete materials for use in rapid repair systems for airport runways. Department of Energy and Environment, Brookhaven National Laboratory, Upton, New York 11973

[68] Tackes, G. (2001). Core binders: a Look to the future. Modern Casting, 31 Oct.
[69] Vazquez, M., Oliva, M., Tellez-Luis, S. J., \& Ramirez, J. A. (2007). Hydrolysis of sorghum straw using phosphoric acid: evaluation of furfural production. Bioresour. Technol., 98, 3053-3060. http://dx.doi.org/10.1016/j.biortech.2006.10.017.

[70] vom Stein, T., Grande, P. M., Leitner, W., \& Dominguez de Maria, P. (2011). Iron-catalyzed furfural production in biobased biphasic systems: from pure sugars to direct use of crude xylose effluents as feedstock. ChemSusChem, 4, 1592-1594. http://dx.doi.org/10.1002/cssc.201100259.

[71] Weingarten, R., Tompsett, G. A., Conner, W. C., Jr., \& Huber, G. W. (2011). Design of solid acid catalysts for aqueous-phase dehydration of carbohydrates: the role of Lewis and Bronsted acid sites. J. Catal., 279, 174-182. http://dx.doi.org/10.1016/j.jcat.2011.01.013.

[72]Werpy, T. A., Petersen, G. (2004). Top value added chemicals from biomass.US Department of Energy, Washington, DC.

[73]Win, D. T. (2005). "Furfural - gold from the garbage". Australian Journal of Technology, 8,185-190.

[74]Wojcik, B. H. (1948). Catalytic hydrogenation of furan compounds. Ind. Eng. Chem., 40, 210-216. http://dx.doi.org/10.1021/ie50458a007.

[75]Xin, F.Y., Liu, Q., Yin, B. Z., Zhu, L. L.,\&Zhu, B. Q. (2009). Clean production method of seaweed fertilizer. China Patent: CNIO1439995 (A)

[76]Xing, R., Qi, W., \& Huber, G.W. (2011). Production of furfural and carboxylic acids from waste aqueous hemicellulose solutions from the pulp and paper and cellulosic ethanol industries. Energy Environ. Sci., 4, 2193-2205. http://dx.doi.org/10.1039/c1ee01022k.

[77] Yang, Y., Hu, C.-W., \& Abu-Omar, M. M. (2012a). Synthesis of furfural from xylose, xylan, and biomass using $\mathrm{AlCl}_{3} \cdot 6 \mathrm{H}_{2} \mathrm{O}$ in biphasic media via xylose isomerization to xylulose. ChemSusChem, 5 , 405-410. http://dx.doi.org/10.1002/cssc.201100688.

[78] Yang, W., Li, P., Bo, D., \& Chang, H. (2012b). The optimization of formic acid hydrolysis of xylose in furfural production. Carbohydr. Res., 357, 53-61. http://dx.doi.org/10.1016/j.carres.2012.05.020.

[79]Yang, W., Li, P., Bo, D., Chang, H., Wang, X., \& Zhu, T. (2013). Optimization of furfural production from $\mathrm{D}$-xylose with formic acid as catalyst in a reactive extraction system. Bioresour. Technol., 133, 361369. http://dx.doi.org/10.1016/j.biortech.2013.01.127.

[80]Yang, W., \& Sen, A. (2011). Direct catalytic synthesis of 5methylfurfural from biomass-derived carbohydrates. ChemSusChem, 4, 349-352. http://dx.doi.org/10.1002/cssc.201000369.

[81]Yuya, T., Takashi, M., Masahiro, F., Ken-ichi, K., \& Masao, K. (2012). Synthesis of biomass-based monomers from biomass-based furfural for polyesters and evaluation of their biomass carbon ratios. ACS Symp. Ser., 1105, 91-110. http://dx.doi.org/10.1021/bk-20121105.ch007.

[82]Zeitsch, K. J. (2000a). Furfural production needs chemical innovation. Chem. Innovation, 30, 29-32

[83]Zeitsch, K. J. (2000b).The chemistry and technology of furfural and its many by-products. Sugar Series: Elsevier Science, Amsterdam, pp 376. 